Concerning the technique of the operation the prevention of infection from the cancer and the prevention of blood loss are two most important factors. My own teclinique is fully described in the Transactions of the Obstetrical Society of Edinburgh, 1911. Finally, I may mention that I have seen recurrence six, seven, and eight years after this operation.I am, etc.

London, W., Jan. 7th.

$$
\text { F. J. McCans. }
$$

SIR,-British gynaecology is under such great obligation to Messrs. Comyns Berkeley and Bonney for the pioneer work they have done in this country for Wertheim's operation that I sincerely regret any suspicion of slight on their work through a little carelessness on my part. In preparing my lecture for publication I eliminated a mass of statistics, retaining Berkeley and Bonney's almost exclusively for this country, but unfortunately by an oversight retained their earlier statistics. I much regret this, though the difference is not nearly so great as would be imagined from Mr. Comyns Berkeley's letter. 'The figures I quoted were:

Mortality, 22.5 per cent.; operability, 67 per cent.; and cure, 26 per cent. for three years;

whereas their later figures in 1916 were :

Mortality, 20 per cent.; operability, 63.5 per cent.; and cure, 39 per cent. for five years.

The last shows a great improvement, and is the only error of any importance.

Dr. Spencer's plea for vaginal hysterectomy in early cases would have more weight with me if there was any certain method of diagnosing the extent of the growth prior to operation. In my experience abdominal section often reveals the growth to be much more extensive than I had estimated by vaginal examination even under the anaestletic. I am, etc.

Manchester, Jan. 9th.

Wiy. Fletcher Shaw.

\section{"LOOSE CARTILAGE."}

SiR,-In your issue of December 17th Mr. Pennell, under the above ticle, states that "the treatment is not easy, and the diagnosis is more difficult still," and that "cures are in the minority." I submit that this unsatisfactory state of affairs is largely due to incorrect diagnosis, but to some extent a!so, as Mr. Pennell states, tc faulty technique in operating. Traumatic affections of the knee-joint are lumped under the blessed term "internal derangements of the knee. joint," and the inexperienced surgeon is apt to follow the line of least resistance and remove the internal or external semi. Junar cartilage as the supposed cause of the disability. I could recount many such cases, but one which has recently come under my notice will suffice to illustrate my point.

An undergraduate injured his knee at football on the last day of the Lent Term. According to his account, the lnee swelled up, but he managed to "go down," and was in. capacitated for the whole of the Easter vacation. On his return to Cambridge lie came to me complaining that the linee frequently "gave way under him, and let him down" On examination I found that there was little or no fluid in the joint, which could be extended to the full. On putting tension on the lateral ligaments in turn, the internal ligament was taut, but the external ligament allowed of considerable separation of the tibia from the external condyle of the femur. There was no histcry of "locking" of the joint. I diagnosed a ruptured external lateral ligament, and prescribed a Marsh's splint with stops to prevent full extension of the joint, advising him to wear this apparatus for at least six months, gradually diminishing the angle of flexion.

I have previously treabed many cases of torn ligaments on these lines with success. To my mind operative measures have little or no advantage, as after suturing the torn ligament the joint has still to be guarded from full extension for a similar period to allow of firm fibrous union of the ligament taking place.

During the Long Tacation he consulted a surgeon near his home, who, I presume; jumped at the diagnosis of loose internal semilunar cartilage, and advised and removed the supposed offender. The patient came to see me the beginning of this (Michaelmas) term. He informed me of the operation and complained that the kueo still frequently gave way. He had, of course, discarded my splint. On examination I observed the operation scar over the inner aspect of the knee. On testing the ligaments as before $I$ fonnd that the external ligament was still loose, but the internal ligament u'as also loose. Thus in the operation for the removal of an inoffensive internal semilunar cartilage the internal lateral ligament had been injured and the condition of the knee rendered rorse than before. All I could advise was a continuance of the splint, strapped as before, to prevent extension of the linee for another six months.

It cannot be denied that there are many traumatic con ditions of the knee which do not admit of accurate diagnosis as to the exact uature of the injury. But there are certain injuries of the joint which can be diagnosed with certainty, and, if correctly diagnosed, treated with every prospect of satisfactory results being obtained. Briefly, it may be stated that "locking of the joint" is pathognomonic of loose or torn semilunar cartilages, but, on the other hand, absence of a history of locking does not necessarily exclude this condition. In the absence of a history of locking and as a routine practice, the internal and external lateral ligaments should always be tested in turn and compared with the sound side. A torn ligament will be demonstrated by the fact that with the knee fully extended the tibia can be separated from tho femur on tension being applied to the injured ligament, a movement which should not obtain if the ligament is taut and intact. These two injuries are produced in two totally different ways. The cartilage is slipped or torn by rotation of the tibia on the femur in a semillexed position of the joint, whereas a lateral ligament is torn by a lateral bending force on the fully extended knee.

A inore accurate knowledge of the anatomy and mechanism of the knee-joint, combined with a carefal inquiry into the history of the accident and a methodical examination of the joint on the lines I have stated, would, I submit, considerably reduce the number of unsatisfactory results of operation on "loose cartilage."-I am, etc.,

Cambridge, Dec. 28th, 1921.

H. B. Roderick.

\section{'TREATMENT OF GONORRHOEA BY ELECTROLYSIS.}

SIR,-The pathology of organic stricture described by Mr. Wyndham Powell is indeed strange reading. He says the superficial layers of epithelium are necrosed and cast off. Because an open ulcer cannot often be seen he misses the off. that their loss is the primary event. The other happenings of cellular renewal, fibrosis and contracture, are really secondary. This disastrous loss of cells is due to localized chemical action, sometimes, perhaps, a bacterial toxin, but much more often due to a caustic. One has only to exaunine a few hundreds of the discharges from cases which have had those applications to find epithelial cells sometimes in groups to be the dominant cellular factor. These cells liave been killed by the chemical applied, and there is a minority of leucocytes-that is, pus cells. This condition is the important feature of films from obstinate cases of gleet. 'This state is initiated by the irritant employed, and is one of the factors which make cases of gonorrhoea chronic.

The benefit which may be obtaned by any such procedure is due to the resulting vascular engorgement of the region of the urethral membrane which has endured such a chemical assault. 'The flow of antibodies is increased with improved phagocytosis of the organisms at work. In my view the price-that is, the damage and necrosis to the partis much too high for the benefit obtained by the method employed.

In a short account of such a group of cases it is impossible to include such a detail as dilatation or other accessory to treatment. Any cases thrat needed it were given dilatation, though most of tho chronic cases had received all that ordinary methods could provide before I saw them. Although a good dilator is a useful instrument it nearly al ways makes a greater impression on the patient than on the bacteria.

With regard to rheumatism my facts can afford to stancl.

Coming next to posterior urethral invasion Mr. Powell seems to forget the common way in which gonococci can reach the epididymis-namely, by the lymph stream. Quite often there is an epididymitis so early in the infection that the lymph highway must have been the path of arrival of the gonococci. Besides this there is the easy and fairly common happening of some tiny lesion of the membrane by a syringe or other object even at the meatus, with the same result.

Even excluding first attacks I am surprised at the rapidity of Mr: Powell's success in curing gonorrhoea by irrigation. Since tlie method is one I never use I can only realiz the contrast of his claim with the time other worker's usually claim in lectures or in published work. 